\title{
Second Law Analysis of Gasoline Powered SI Engines with Hydrogen Injection
}

\author{
Ismail I. HDAIB, Jehad A. A. YAMIN*, Eiman Ali Eh SHEET
}

\begin{abstract}
A simulation study on the effect of hydrogen addition as supplementary fuel to gasoline at lean mixture (equivalence ratio $\phi=0.8$ ) was carried out in order to reduce the gasoline fuel consumption and harmful emissions. The effect on the first law, emissions, and second law parameters was investigated. This was done by changing the mixture ratio between gasoline and the supplementary fuels to achieve the required equivalence ratio. The first part (first law and emission performance) was conducted for all engine speeds. The second part (second law analysis) was done at the rated speed of $2750 \mathrm{rpm}$. The simulation study was performed using the date for (Ricardo E6/T variable compression ratio engine), which was used for model verification. The study showed that at lean mixture, hydrogen addition reduced carbon monoxide and nitrogen oxides levels. Hydrogen addition significantly improved the heat release rate; however, due to its fast burning speed, the heat released was close to the top dead centre compared with gasoline. From second law analysis, hydrogen addition caused a slight drop in the work availability, increased availability loss with heat, and an increase in the area under temperature entropy diagram.
\end{abstract}

Keywords: entropy; engine availability; engine emissions; Gasoline - $\mathrm{H}_{2}$; hydrogen fuel; lean-burn engine

\section{INTRODUCTION}

The world is consuming its conventional energy sources (mostly fossil) at rapid rates to meet its growing demand. Due to their nature of usage, the consumption of such fossil fuels resulted in environmental problems that have reached an alarming rate. This problem manifested itself in the form of greenhouse gases, depletion of the ozone layer, acid rain, etc. This necessitates the need to find more eco-friendlier energy sources.

Several properties possessed by hydrogen made it more preferable compared with the conventional spark ignition (SI) engine fuels, i.e., gasoline [1-6].

Hydrogen has a four times higher diffusion coefficient than that for gasoline; this helps better mixing and more homogeneity of the fuel mixture. Hydrogen has nearly five times the adiabatic flame speed compared to that for gasoline; this means more stable engine operation and combustion process closer to constant volume; this also helps improve engine thermal efficiency.

On the other hand, higher adiabatic flame temperature means higher NOx levels. Further, hydrogen suffers from one more severe drawback, i.e., the energy density of the fuel calculated on a volume basis is much lower than that for gasoline. This adversely affects the engine out torque. Hydrogen, as shown in Tab. 1, has a higher flammability range and lower minimum ignition energy compared with gasoline. This makes the hydrogen-gasoline blend easier to ignite and better combustion stability under lean conditions.

The use of hydrogen as mono and dual fuel for the SI engine has been subjected to a considerable amount of research by scientists. Some discussed the use of hydrogen as supplementary fuel for gasoline; others discussed its use with compressed natural gas $(\mathrm{CNG})$ engine performance [7-11].

An extensive review of the use of hydrogen as a fuel for internal combustion engines (ICE) is shown in [12-15]. The significant advantages and effects on engine performance, as well as the main difficulties and problems in implementing hydrogen, were also discussed.

The effect of engine design and operating parameters, e.g., compression ratio (CR), combustion chamber surface/volume $(\mathrm{S} / \mathrm{V})$ ratio, and the boost pressure on engine efficiency and emissions were studied in [16].

They reported an increase in engine efficiency with a decrease in the $\mathrm{S} / \mathrm{V}$ ratio with a reduction in NOx level. Martinez-Boggio et al. [17] reported that there is an optimum hydrogen blending percentage with gasoline (by volume) that prevents cycle-to-cycle variations. This percentage is a characteristic of the air-fuel ratio.

Mohammad Kamil et al. [18] found that the output power of the engine dropped by $<6 \%$ with a $10 \%$ hydrogen addition to gasoline.

D'Andrea et al. [19] studied the use of hydrogen blended with gasoline at different engine speeds and equivalence ratios on the combustion process. They reported lesser cyclic variations and decreased combustion durations with hydrogen addition.

Varde [20] studied the engine operational stability using hydrogen-gasoline bends. He found that combustion durations were reduced with the extension on lean burn limits with hydrogen addition.

Dimopoulos et al. [21] also proved that with the help of hydrogen injection as pilot fuel, greenhouse emissions could be reduced.

Other researchers [22, 23] showed improvement in engine thermal efficiency and emissions except for $\mathrm{HC}$ and $\mathrm{CO}$ emissions at around $5 \%$ hydrogen volume fraction.

Sher et al. [24] and Jing-Dinget al. [25] showed reduction in the brake specific fuel consumption of the gasoline engine at lean equivalence ratios with hydrogen addition.

From a second law analysis point of view, HakanOzcan [26] conducted a theoretical analysis on the use of hydrogen as supplement fuel for CNG fuelled SI engine. He concluded that hydrogen addition had a noticeable effect on engine availability. Combustion irreversibilities decreased while second law efficiency increased with hydrogen addition.

Rakopoulos and Kyritsis [27, 28] studied the effect of hydrogen enrichment on the second law performance of an engine powered with natural gas and landfill gas. They also reported a reduction in combustion irreversibility and, as a consequence, improvement in second law efficiency with increasing proportions of hydrogen. 


\subsection{Fuel Properties}

Tab. 1 shows some of the significant properties of hydrogen and gasoline as fuels for SI engines. It can be noticed that hydrogen is a very light gaseous fuel compared with other fuels.

It needs (on a volume basis) the least amount of stoichiometric combustion air (2.39 compared with 59.6 for gasoline). On the other hand, it needs the highest amount of stoichiometric combustion air on a mass basis (34 for hydrogen compared with 14.7 for gasoline).

It has the highest calorific value on a mass basis (lowest value on a volume basis). On a mass basis, it has the highest stoichiometric combustion energy released. Hydrogen has the highest octane number amongst other fuels, which makes it excellent resistant to knocking.

Table 1 Properties of fuels
\begin{tabular}{|l|c|c|}
\hline \multicolumn{1}{|c|}{ Property } & Gasoline & Hydrogen \\
\hline Density at 1 atm and 300 / K kg/m ${ }^{3}$ & $720-760$ & 0.082 \\
\hline Stoichiometric A/F ratio (by volume) & 59.5 & 2.39 \\
\hline Research Octane Number & $90-100$ & 130 \\
\hline Lower Heating Value / MJ/kg & 43.448 & 119.7 \\
\hline Flammability Limits / \% Volume & $1.2-6.0$ & $4-75$ \\
\hline Minimum Ignition Energy / mJ & 0.25 & 0.02 \\
\hline Laminar Flame Speed at NTP / m/s & $0.37-0.43$ & $\sim 2.0$ \\
\hline Adiabatic Flame Temperature / ${ }^{\circ} \mathrm{C}$ & $\sim 2470$ & 2318 \\
\hline
\end{tabular}

It has excellent diffusive and heat transfer characteristics due to its low density and luminosity. Hydrogen has wider flammability limits. This enables it to run leaner and hence improve engine fuel economy. The lower minimum energy value needed for ignition makes it burn faster and better than other fuels.

The data given in the above table, as well as the discussion stated before, suggests that there is a need to consider the significant difference between the two different fuels and their blends on designing or modifying the engine. Not doing so may cause some problems associated with the fast combustion of hydrogen compared with gasoline (e.g. fast rate or pressure rise due to higher flame speed, knocking if maximum pressure occurs near top dead center or early during compression stroke etc. both of which cause loss in power and increase heat loss.

One way of properly utilizing the supplementary fuel is to understand how it affects the engine operation. Most of the above research focused on the first law analysis. This study will combine both the first and second law analysis of using two different fuels as supplement fuel to gasoline at lean operation.

There are several advantages for running the engine with lean Air/Fuel ratio. Keeping the combustion temperature low, thus, the NOx levels also low, the engine's combustion efficiency improves.

This also reduces the tendency of the engine to produce knocking, hence, can be run at higher compression ratios.

Leaner A/Fuel ratio mixtures have the advantage of higher specific heat ratios. This helps improve the thermal efficiency of the engine.

Further, running the engine at leaner Air/Fuel ratios limits the emissions of certain species.

On the other hand, with leaner Air/Fuel ratios, the combustion instabilities, cycle-to-cycle variations (CCV) become high. These factors limit the lean limits of the Air/Fuel ratios that can be used.
The main objective is to try to understand (from the second law point of view) how much was the maximum available energy and how much went as a loss. Further, this study will be conducted at a lean mixture to try to extend the lean limit of the engine with gasoline to lower fuel consumption, improve fuel utility, and reduce emissions. The equivalence ratio selected for this study was 0.8 , which lies off the maximum $\mathrm{NOx}$ and $\mathrm{CO}_{2}$ points.

\subsection{The Engine}

The engine used for this study to verify the mathematical model was the Ricardo E6/T, 4-stroke, water-cooled variable stroke engine. The model is well verified for this engine and has been tested for other fuels and variables. The basic engine specifications are shown below in Tab. 2 .

Table 2 Engine Specification

\begin{tabular}{|l|l|}
\hline \multicolumn{1}{|c|}{ Engine Parameter } & \multicolumn{1}{c|}{ Value } \\
\hline Type & Ricardo E6/T \\
\hline Bore $\times$ Stroke & $76.2 \times 111.125 \mathrm{~mm}$ \\
\hline Displacement volume & $504 \mathrm{~cm}^{3}$ \\
\hline Engine speed & Variable \\
\hline Compression Ratio & $8: 1$ (fixed) \\
\hline Spark Advance & $20^{\circ}$ bTDC \\
\hline Throttle Position & Wide Open (WOT) \\
\hline
\end{tabular}

\section{Theoretical Analysis}

A zero-dimensional, two-zone thermodynamic cycle simulation with a two-zone combustion model, mainly based on the model described in $[6,23]$ and their relative modifications, was used in this work. The working medium was considered, in general, as a mixture of the following 11 species: $\mathrm{O}_{2}, \mathrm{~N}_{2}, \mathrm{CO}_{2}, \mathrm{H}_{2} \mathrm{O}, \mathrm{H}_{2}, \mathrm{OH}, \mathrm{NO}, \mathrm{CO}, \mathrm{O}, \mathrm{H}$, and $\mathrm{CH}_{4}$.

Wiebe functions [29] shown in Eq. (1) were used to model the mass fraction burned variation with crank angle as follows:

$x_{b}=\frac{m_{b}}{m_{m i x}}=1-\left[-\alpha\left(\frac{\theta-\theta_{0}}{\Delta \theta_{b}}\right)^{m+1}\right]$

where $x_{b}$ is the mass fraction burned ND), $m_{b}$ is the mass burned $(\mathrm{kg}), m_{\text {mix }}$ is the total mixture inside the cylinder $(\mathrm{kg}), \theta$ is the crank angle (deg), $\theta_{o}$ is the start of combustion (deg), $\Delta \theta_{b}$ is the burning duration (deg), and $a$ and $m$ are model constants.

The rate of heat released (derivative of the mass fraction burned with crank angle) is given by the following equation:

$$
\frac{\mathrm{d} x_{b}}{\mathrm{~d} \theta}=\left(\alpha \frac{m+1}{\Delta \theta_{b}}\right)\left(\frac{\theta-\theta_{0}}{\Delta \theta_{b}}\right)^{m}=1-\left[-\alpha\left(\frac{\theta-\theta_{0}}{\Delta \theta_{b}}\right)^{m+1}\right]
$$
by:

The rate of availability transfer with work $\left(A_{w}\right)$ is given

$\frac{\mathrm{d} A_{w}}{\mathrm{~d} \theta}=\left(p-p_{0}\right)\left(\frac{\mathrm{d} V}{\mathrm{~d} \theta}\right)$ 
where; $P$ is the cylinder pressure $(\mathrm{kPa}), P_{\mathrm{o}}$ is the atmospheric or dead state pressure $(\mathrm{kPa})$ which is $100 \mathrm{kPa}$, $V$ is the cylinder volume $\left(\mathrm{m}^{3}\right)$. The derivative of volume with crank angle can be written as:

$\frac{\mathrm{d} V}{\mathrm{~d} \theta}=\frac{V}{2} \sin (\theta)\left[\frac{\cos (\theta)}{\sqrt{\left(\frac{2 C R L}{S}\right)^{2}+\sin ^{2}(\theta)}}-1\right]$

where: $V S$ is the cylinder swept volume $\left(\mathrm{m}^{3}\right), C R L$ is the connecting rod length $(\mathrm{m})$ and $S$ is the stroke length $(\mathrm{m})$.

The expression for the rate of availability transfer due to irreversible heat transfer $\left(A_{L}\right)$ is given by:

$\frac{\mathrm{d} A_{L}}{\mathrm{~d} \theta}=\frac{\mathrm{d} Q_{L}}{\mathrm{~d} \theta}\left(1-\frac{T_{0}}{T}\right)$

where: $Q_{L}$ is the heat lost to coolant during the cycle (W), $T$ is the cylinder temperature $(\mathrm{K})$ and $T_{0}$ is the dead state temperature $(\mathrm{K})$ which is $293 \mathrm{~K}$.

The rate of availability of the fuel $\left(A_{f}\right)$ that is introduced into the process:

$$
\begin{aligned}
& \frac{\mathrm{d} A_{f}}{\mathrm{~d} \theta}=\left(1-x_{b}\right)\left(\frac{\mathrm{d} x_{b}}{\mathrm{~d} \theta}\right) a_{f} \\
& a_{f}=L H V_{f}\left[1.0334+0.0183 \frac{H}{C}-0.0694 \frac{1}{C}\right]
\end{aligned}
$$

A comprehensive discussion on the formulations of the second law analysis of engine combustion can be found in [30-34].

In this study, the mixture was varied, keeping the overall trapped equivalence ratio $=0.8$. The ignition timing was kept constant at $20^{\circ} \mathrm{bTDC}$ as in the engine design.

Since the main aim of the research is to keep the fossil fuel used (i.e., gasoline) minimum, the gasoline flow rate was adjusted to keep the equivalence ratio $=0.8$.

First, the engine simulation was run on an equivalence ratio of 0.8 using gasoline fuel to set the baseline (or reference) performance. Based on that, the mass flow of fuel was found. Then hydrogen fuel was added in specific amounts such that the overall equivalence ratio $(\phi)$ remains the same at 0.8 .

This was done by adjusting (reducing) gasoline mass to give the overall equivalence ratio $\phi=0.8$. At first, the engine requirements with gasoline were found, then hydrogen was introduced to the engine, and the amount of gasoline was readjusted to maintain the equivalence ratio at 0.8 .

\section{RESULTS AND DISCUSSION}

The results are divided into two main parts, i.e., part (a) deals with first law performance parameters while part (b) deals with second law parameters.

Before starting the discussion part, model validation must be ascertained. This is clearly shown in Fig. 1 and
Fig. 2. Those figures show that the model was able to predict the performance of the engine to a good degree of accuracy.

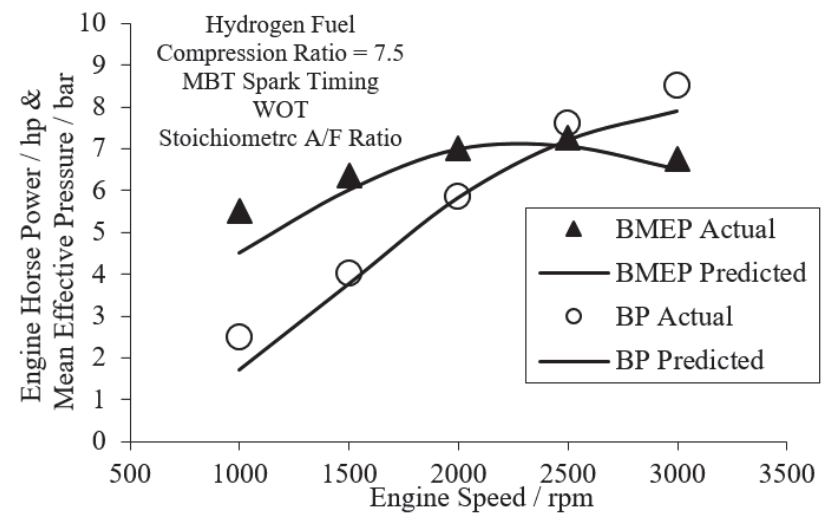

Figure 1 Model verification for engine power

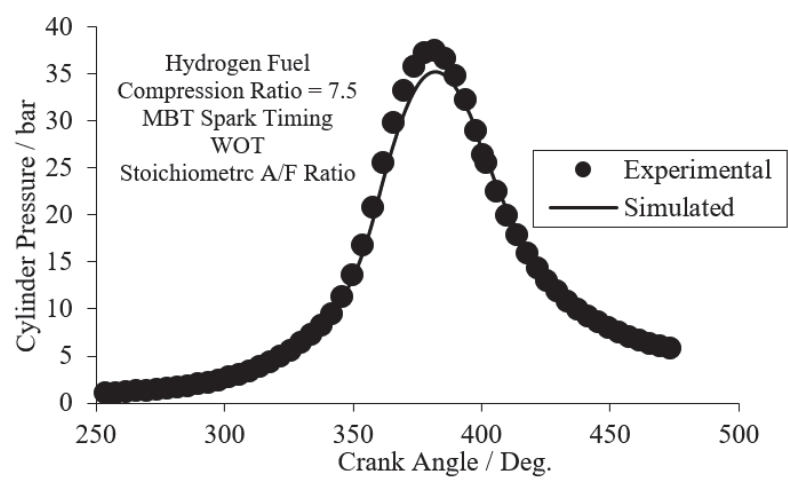

Figure 2 Model verification for in-cylinder pressure

\subsection{Brake Power}

Brake power (BP) is a parameter that reflects the engine power output. Fig. 3 shows the engine's BP with hydrogen enrichment. It can be seen from Fig. 3 that BP increases with the addition of hydrogen fuel.

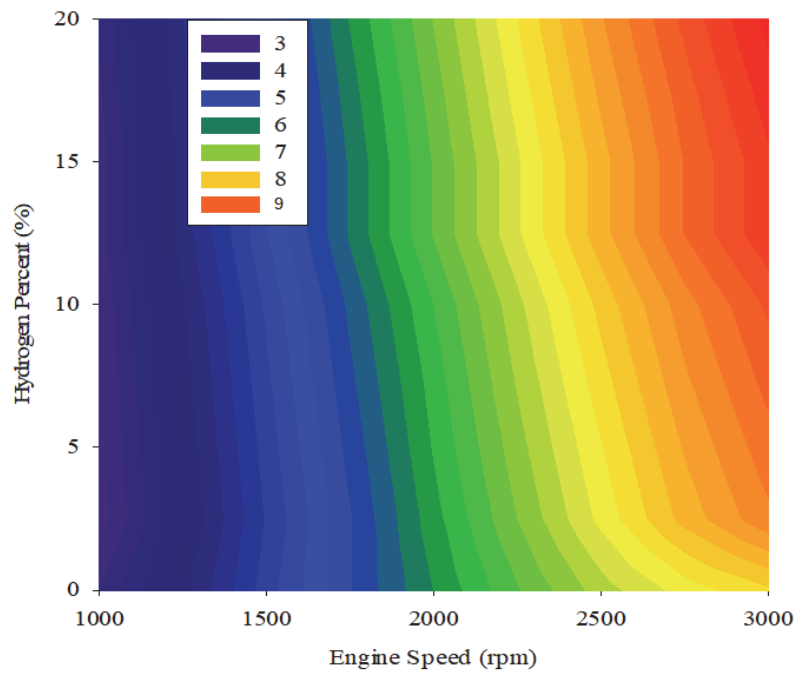

Figure 3 Variation of brake power $(\mathrm{kW})$ with engine speed and hydrogen addition

It is also shown in Fig. 1 that BP increment becomes noticeable beyond 5\%. To understand this trend, Fig. 4 shows the peak cylinder pressure (drawn for the engine rated power speed, i.e., $2750 \mathrm{rpm}$, ignition at $20^{\circ} \mathrm{bTDC}$ ). 
It can be seen that the peak cylinder pressure increases with an $\mathrm{H}_{2}$ percentage in the mixture. However, this peak pressure occurs close to TDC with higher pressures for hydrogen.

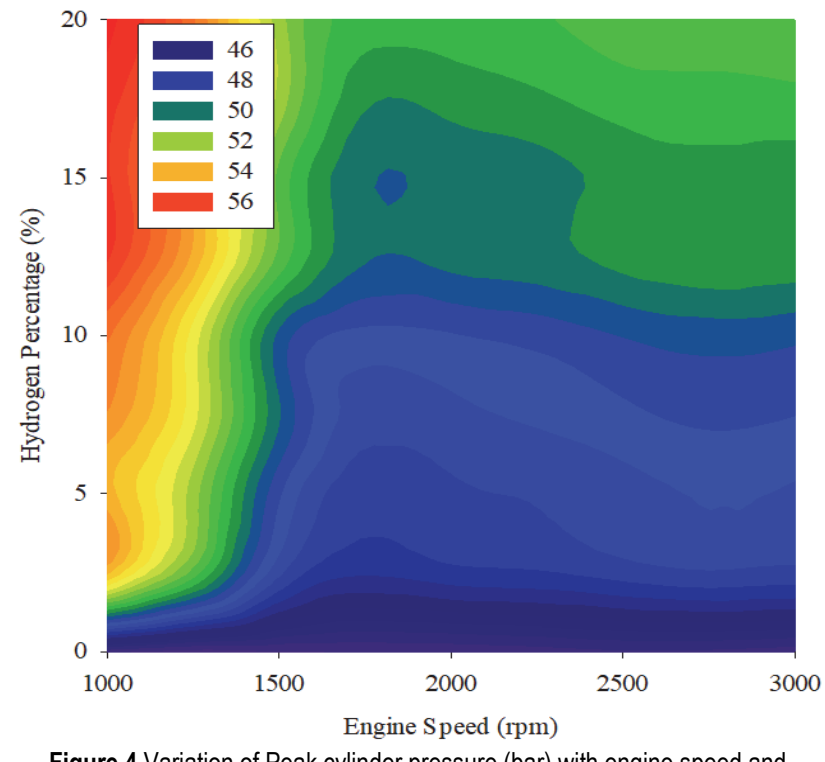

Figure 4 Variation of Peak cylinder pressure (bar) with engine speed and hydrogen addition

Several reasons were suggested for such behaviour based on the energy content of the mixture flowing into the cylinder with hydrogen increment and the pure effect of constant spark timing $[1,2]$.

Whereas hydrogen tends to decrease the energy content due to lower energy content on a volume basis, in addition to the heating effect of inlet manifold, which causes the gaseous fuel to expand, thus applying some restrictions on the flow of air into the engine.

\subsection{Brake Thermal Efficiency}

Thermal efficiency of the engine is inversely related to the fuel economy (for the same fuel). As the thermal efficiency of the engine increases, it indicates better utilization of the engine to the input energy coming with the fuel.

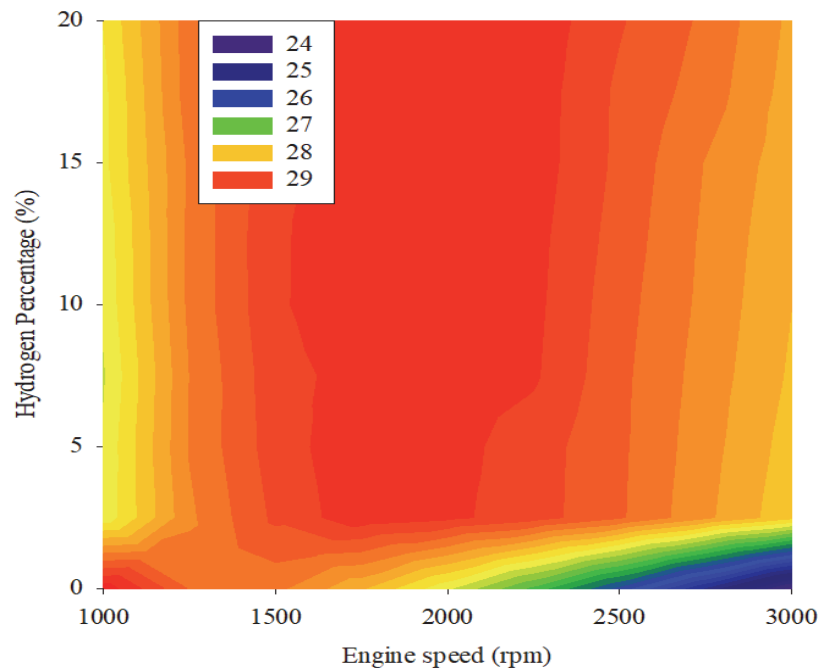

Figure 5 Variation in brake thermal efficiency (\%) with engine speed and hydrogen addition
The relative change in brake thermal efficiency with engine speed is shown in Fig. 5. As seen in Fig. 5, hydrogen-enriched engines showed higher efficiency values compared with gasoline, especially at higher fuel fraction. Moreover, at lower engine speeds, thermal efficiency for the engine with both fuels is less than the original fuel.

As a result of the high energy input and higher burning efficiency, Fig. 6 shows two main points, first, the percentage of heat loss is higher with hydrogen addition.

Further, heat loss decreases with engine speed. One possible reason for this behaviour is the shorter duration of combustion with hydrogen due to faster flame speed; hence, less time will be available for the products of combustion to lose their energy.

\subsection{Heat Release Rate (HRR)}

Many factors are known to affect the engine's thermal efficiency. Among those factors come the combustion related factors (e.g. flame propagation, development, and combustion duration). Fig. 7 shows the HRR for all fuels at all engine speeds.

As can be seen in the figure, the rate of heat release for $\mathrm{H}_{2}$ fuel is higher than that for pure gasoline. The figure also shows that the rate of heat release (RoHR) for the hydrogen-gasoline blend is higher than that with pure gasoline.

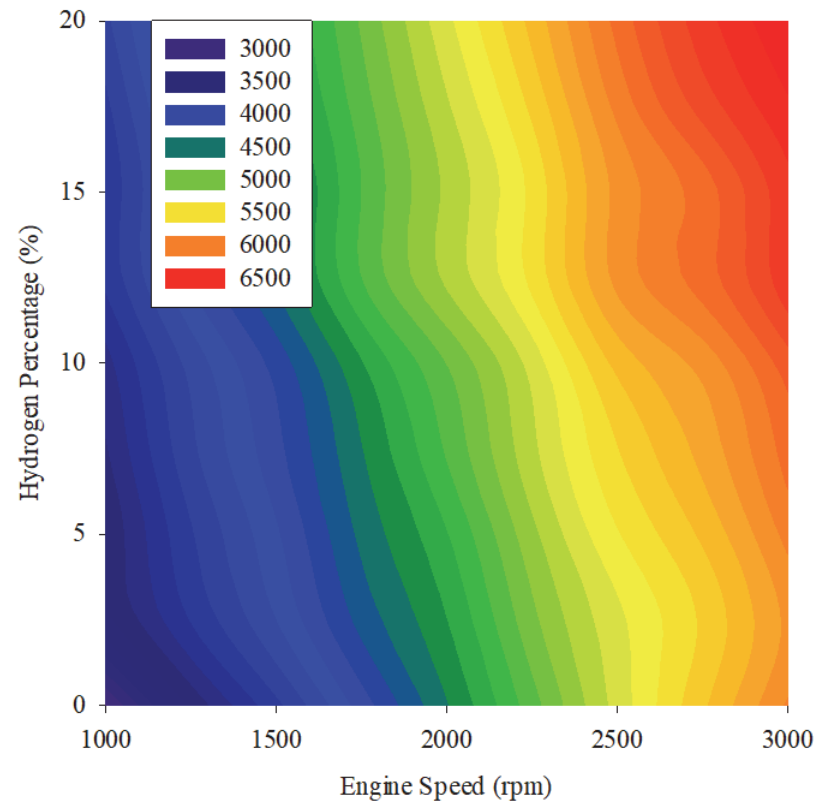

Figure 6 Variation of heat loss (W) with engine speed and hydrogen addition

The peak difference between both fuels is about $20 \%$ in favour of hydrogen. This is expected due to the higher energy content for hydrogen compared with gasoline.

Further noticed, the angle at peak RoHR increases with hydrogen addition, and the effect is more significant for the case of hydrogen addition compared with pure gasoline. This can be attributed to the generation of the radicals (e.g. $\mathrm{OH})$ in the cylinder, which helps reduce the combustion duration (by improving the flame growth period and propagation) $[1,2]$. 


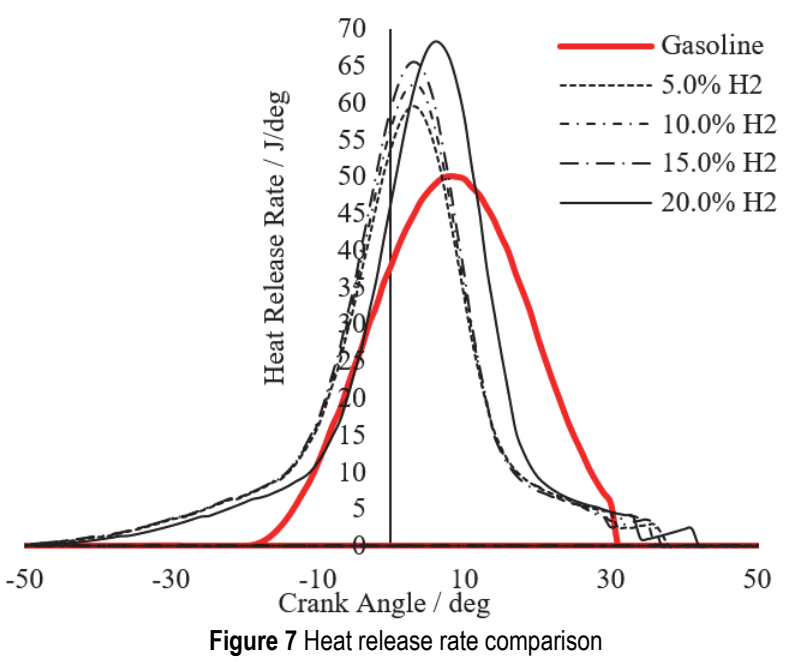

\subsection{Engine Availability Analysis}

From the second law point of view, Fig. 8 shows that the energy transferred with work is more significant for gasoline fuel compared with hydrogen. Further, it shows that $\mathrm{H}_{2}$ fuel, the exergy transferred with work inside the cylinder, is higher than that for gasoline.

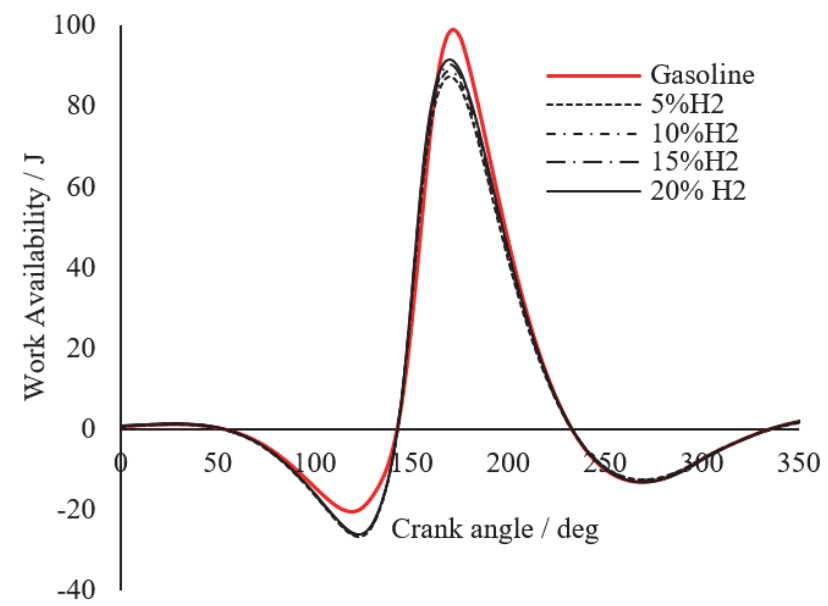

Figure 8 Work Availability

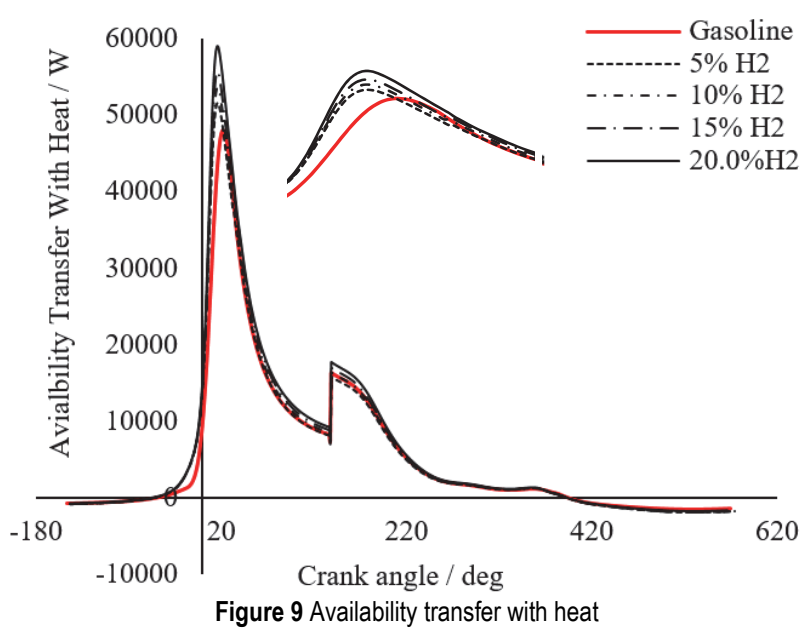

This trend helps explain why the engine tends to develop more power with $\mathrm{H}_{2}$ addition at this equivalence ratio for these study parameters (injection and ignition timing) compared with gasoline. The amount of energy transferred with heat is shown in Fig. 9.

There is a clear trend that the amount of exergy that is transferred with heat is higher than that for gasoline. Further, the amount transferred is slightly greater for hydrogen. The amount of energy transferred increases with that of the fuel added.

This figure helps explain the increase in heat loss with hydrogen. Further, it helps explain the gain in thermal efficiency for hydrogen addition.

Fig. 10 shows the variation of cylinder temperature with entropy inside the cylinder.

This figure helps visualize the heat transfer inside the engine during the processes. It can be well understood with the help of the above figures. This figure shows higher values of temperatures at almost the same entropy value during the combustion process. Further, for the same temperature value, the value of entropy for gasoline is lower than that for $\mathrm{H}_{2}$ addition.

This helps explain the trend shown in Fig. 5 and Fig. 6 , whereby the engine suffered higher energy loss and lower thermal efficiency as a result of higher heat transferred. On the other hand, the overall cycle shows that the area under the curve for $\mathrm{H}_{2}$ addition is higher than that with gasoline. This helps explain the trend shown by Fig. 3 and Fig. 8 since the overall area can be understood to be the total work output done by the engine. Similar results are shown by [6].

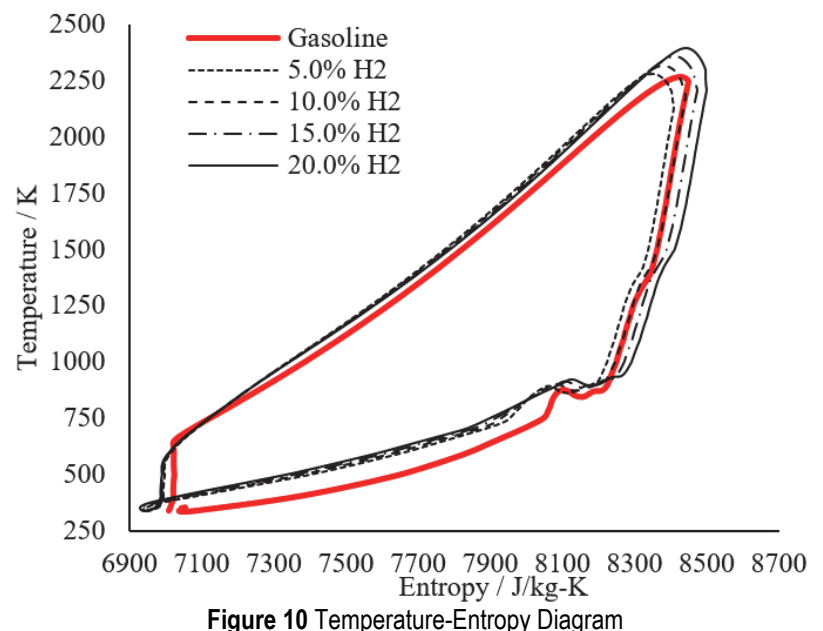

\section{CONCLUSIONS}

A study on the effect of hydrogen addition as supplementary fuel for gasoline engine at lean mixture $(\phi$ $=0.8$ ) was conducted. The effect on the first law, emissions, and second law parameters were conducted.

The study clearly shows that at lean mixture, hydrogen addition significantly improves the HRR; however, due to its fast burning nature, the heat released was close to the top dead centre compared with gasoline.

Up to $15 \%$ of hydrogen edition was found suitable for engine performance and emissions. Hydrogen addition increased the entropy of the cycle, energy transfer with heat and lowered the energy transferred with work. Hydrogen addition of up to $5 \%$ was the best amongst the ratios studied from second law performance point of view. 
Hydrogen has a more significant and visible influence on engine first law performance than pure gasoline.

\section{REFERENCES}

[1] Ji, C. \& Wang, S. (2009). Effect of hydrogen addition on combustion and emissions performance of a spark ignition gasoline engine at lean conditions. International Journal Of Hydrogen Energy, 34(18), 7823-7834. https://doi.org/10.1016/j.jijhydene.2009.06.082

[2] Ji, C. \& Wang, S. (2009). Effect of hydrogen addition on the idle performance of a spark ignited gasoline engine at stoichiometric condition. International journal of hydrogen Energy, 34(8), 3546-3556. https://doi.org/10.1016/j.jighdene.2009.02.052

[3] Karim, G. A. (2003). Hydrogen as a spark ignition engine fuel. International Journal of Hydrogen Energy, 28(5), 569577. https://doi.org/10.1016/S0360-3199(02)00150-7

[4] Sheet, E. A. E. (2016). Performance and Sensitivity analysis of Factors Affecting NOx Emissions from Hydrogen Fueled SI Engines. Journal of Petroleum Research \& Studies, 120(12th), 47-74. https://doi.org/10.52716/jprs.v6i2.148

[5] Verma, G., Prasad, R. K., Agarwal, R. A., Jain, S., \& Agarwal, A. K. (2016). Experimental investigations of combustion, performance and emission characteristics of a hydrogen enriched natural gas fuelled prototype spark ignition engine. Fuel, 178, 209-217. https://doi.org/10.1016/j.fuel.2016.03.022

[6] Yamin, J. A. (2006). Comparative study using hydrogen and gasoline as fuels: Combustion duration effect. International journal of energy research, 30(14), 1175-1187. https://doi.org/10.1002/er.1213

[7] Shrestha, S. B. \& Karim, G. A. (1997). Hydrogen as an additive to methane for spark ignition engine applications. In IECEC-97 Proceedings of the Thirty-Second Intersociety Energy Conversion Engineering Conference (Cat. No. 97CH6203), 2, 910-915. https://doi.org/10.1109/IECEC.1997.661890

[8] Bauer, C. G. \&Forest, T. W. (2001). Effect of hydrogen addition on the performance of methane-fueled vehicles. Part I: effect on SI engine performance. International Journal of Hydrogen Energy, 26(1), 55-70. https://doi.org/10.1016/S0360-3199(00)00067-7

[9] Ma, F., Ding, S., Wang, Y., Wang, Y., Wang, J., \& Zhao, S. (2008). Study on combustion behaviors and cycle-by-cycle variations in a turbocharged lean burn natural gas SI engine with hydrogen enrichment. International Journal of Hydrogen Energy, 33(23), 7245-7255. https://doi.org/10.1016/j.jijhydene.2008.09.016

[10] Ma, F., Wang, Y., Wang, M., Liu, H., Wang, J., Ding, S., \& Zhao, S. (2008). Development and validation of a quasidimensional combustion model for SI engines fuelled by HCNG with variable hydrogen fractions. International Journal of Hydrogen Energy, 33(18), 4863-4875. https://doi.org/10.1016/j.jijhydene.2008.06.068

[11] Dunn-Rankin, D. (Ed.). (2011). Lean combustion: technology and control. Academic Press.

[12] Veziroglu, T. N. (2007). 21st Century's energy: Hydrogen energy system. In Assessment of hydrogen energy for sustainable development, 9-31. Springer, Dordrecht. https://doi.org/10.1007/978-1-4020-6442-5_2

[13] Ball, M. \& Wietschel, M. (2009). The future of hydrogenopportunities and challenges. International journal of hydrogen energy, 34(2), 615-627. https://doi.org/10.1016/j.jigydene.2008.11.014

[14] White, C. M., Steeper, R. R., \& Lutz, A. E. (2006). The hydrogen-fueled internal combustion engine: a technical review. International Journal of Hydrogen Energy, 31(10), 1292-1305. https://doi.org/10.1016/j.jighydene.2005.12.001
[15] Steeper, R. R.; White, C. M., \& Lutz, A. E. (2005). The hydrogen-fueled internal combustion engine: a technical review (No. SAND2005-3057J). Sandia National Laboratories.

[16] Nakajima, Y., Yamane, K., Shudo, T., Hiruma, M., \& Takagi, Y. (2000). Research and development of a hydrogenfueled engine for hybrid electric vehicles. SAE transactions, 1175-1179. https://doi.org/10.4271/2000-01-0993

[17] Martínez-Boggio, S. D., Curto-Risso, P. L., Medina, A., \& Hernández, A. C. (2016). Simulation of cycle-to-cycle variations on spark ignition engines fueled with gasolinehydrogen blends. International Journal of Hydrogen Energy, 41(21), 9087-9099. https://doi.org/10.1016/j.ijhydene.2016.03.120

[18] Kamil, M. \& Rahman, M. M. (2015). Performance prediction of spark-ignition engine running on gasolinehydrogen and methane-hydrogen blends. Applied energy, 158, 556-567. https://doi.org/10.1016/j.apenergy.2015.08.041

[19] D'andrea, T., Henshaw, P. F., \& Ting, D. K. (2004). The addition of hydrogen to a gasoline-fuelled SI engine. International journal of hydrogen energy, 29(14), 15411552. https://doi.org/10.1016/j.ijhydene.2004.02.002

[20] Varde, K. S. (1981). Combustion characteristics of small spark ignition engines using hydrogen supplemented fuel mixtures (No. 810921). SAE Technical Paper. https://doi.org/10.4271/810921

[21] Dimopoulos, P., Bach, C., Soltic, P., \& Boulouchos, K. (2008). Hydrogen-natural gas blends fuelling passenger car engines: combustion, emissions and well-to-wheels assessment. International journal of hydrogen energy, 33(23), 7224-7236. https://doi.org/10.1016/j.ijhydene.2008.07.012

[22] Ji, C., Wang, S., \& Zhang, B. (2010). Combustion and emissions characteristics of a hybrid hydrogen-gasoline engine under various loads and lean conditions. International journal of hydrogen energy, 35(11), 57145722. https://doi.org/10.1016/j.ijhydene.2010.03.033

[23] Wang, M. (2008). The greenhouse gases, regulated emissions, and energy use in transportation (GREET) model: Version 1.5. Center for Transportation Research, Argonne National Laboratory.

[24] Sher, E. \& Hacohen, Y. (1989). Measurements and predictions of the fuel consumption and emission of a spark ignition engine fuelled with hydrogen-enriched gasoline. Proceedings of the Institution of Mechanical Engineers, Part A: Journal of Power Engineering, 203(3), 155-162. https://doi.org/10.1243/PIME_PROC_1989_203_022_02

[25] Jing-Ding, L., Ying-Qing, L., \& Tian-shen, D. (1986). Improvement on the combustion of a hydrogen fueled engine. International Journal of hydrogen energy, 11(10), 661-668. https://doi.org/10.1016/0360-3199(86)90007-8

[26] Ozcan, H. (2010). Hydrogen enrichment effects on the second law analysis of a lean burn natural gas engine. International Journal of Hydrogen Energy, 35(3), 14431452. https://doi.org/10.1016/j.ijhydene.2009.11.039

[27] Rakopoulos, C. D. \& Kyritsis, D. C. (2006). Hydrogen enrichment effects on the second law analysis of natural and landfill gas combustion in engine cylinders. International Journal of Hydrogen Energy, 31(10), 1384-1393. https://doi.org/10.1016/j.jijhydene.2005.11.002

[28] Rakopoulos, C. D., Scott, M. A., Kyritsis, D. C., \& Giakoumis, E. G. (2008). Availability analysis of hydrogen/natural gas blends combustion in internal combustion engines. Energy, 33(2), 248-255. https://doi.org/10.1016/j.energy.2007.05.009

[29] Ghojel, J. I. (2010). Review of the development and applications of the Wiebe function: a tribute to the contribution of Ivan Wiebe to engine research. International Journal of Engine Research, 11(4), 297-312. https://doi.org/10.1243/14680874JER06510 
[30] Ferguson, C. R. \& Engines, I. C. (2015). Applied thermosciences. Internal Combustion Engines.

[31] Benson, R. S. (1971). A comprehensive digital computer program to simulate a compression ignition engine including intake and exhaust systems (No. 710173). SAE Technical Paper. https://doi.org/10.4271/710173

[32] Caton, J. A. (2002). A cycle simulation including the second law of thermodynamics for a spark-ignition engine: implications of the use of multiple-zones for combustion. SAE Transactions, 281-299. https://doi.org/10.4271/2002-01-0007

[33] Karagöz, Y. (2018). Effect of hydrogen addition at different levels on emissions and performance of a diesel engine. Journal of Thermal Engineering, 4(2), 1780-1790. https://doi.org/10.18186/journal-of-thermal-engineering.372968

[34] Sharma, P. \& Dhar, A. (2018). Effect of hydrogen supplementation on engine performance and emissions. International Journal of Hydrogen Energy, 43(15), 75707580. https://doi.org/10.1016/j.ijhydene.2018.02.181

\section{Contact information:}

Ismail I. HDAIB, Assistant professor

Department of Renewable Energy Engineering, Faculty of Engineering,

Isra University, Amman 11622, Jordan

Phone: 00962798418429

E-mail: ismail.hdaib@iu.edu.jo

Jehad A. A.YAMIN, Associate Professor

(Corresponding author)

Department of Mechanical Engineering

School of Engineering, The University of Jordan,

Amman 11942, Jordan

Phone: 00962799609750

E-mail: yamin@ju.edu.jo

Eiman Ali Eh SHEET, Retired Lecturer

Energy and Renewable Energies Technology Center,

University of Technology-Iraq,

Baghdad 10066, Al Senaa Street, Iraq

Phone: 009647703995667

E-mail:11010@uotechnology.edu.iq 